\title{
HUBUNGAN TINGKAT PENGETAHUAN DENGAN KEMAMPUAN PEMERIKSAAN DADA SENDIRI (SADARI) PADA WANITA USIA SUBUR DI DESA SUKODADI KECAMATAN WAGIR KABUPATEN MALANG
}

\author{
Susmini ${ }^{1}$, Supriyadi ${ }^{2}$ \\ 1,2 Dosen Program Studi Keperawatan Universitas Tribhuwana Tunggadewi \\ E-mail : flowerensia29@gmail.com
}

\begin{abstract}
High caused of mortality rate because of breast cancer, needs early detection to diagnose cancer symptoms. One of them is breast self-examination (BSE). Breast self-examination is an early screening that women can do by self to detect abnormalities in their breast, so can determine diagnosis early and give management be right. This study aims to determine the relationship between the level of knowledge and the abilities to examine breast self-examination in fertiled women at Desa Sukodadi Kecamatan Wagir Kabupaten Malang. The design of the research was cross sectional, the sample of 28 respondents fertiled women chosen through simple random sampling technique. The results of Chi Square test was $0.008<p$ value 0.05 it indicates there are the relationship between the level of knowledge and the abilities to examine breast self-examination in fertiled women at Desa Sukodadi Kecamatan Wagir Kabupaten Malang. The next researcher can examine the analysis factors to affect womens awareness and willingness to do breast self-examination.
\end{abstract}

Keywords : Knowledge, ability, breast self-examination

\begin{abstract}
Abstrak : Kematian yang disebabkan karena kanker payudara masih cukup tinggi, perlu adanya deteksi dini untuk mendiagnosis gejala kanker. Salah satunya ialah pemeriksaan dada sendiri (SADARI). SADARI merupakan skrining awal yang bisa dilakukan wanita secara mandiri untuk mendeteksi kelainan yang terjadi pada payudara, sehingga dapat mententukan diagnosa lebih awal dan penatalaksanaan dapat segera dilakukan. Penelitian ini bertujuan untuk mengetahui hubungan antara Tingkat Pengetahuan Dengan Kemampuan Pemeriksaan Dada Sendiri (SADARI) Pada Wanita Usia Subur Di Desa Sukodadi Kecamatan Wagir Kabupaten Malang. Desain penelitian ini menggunakan Cross Sectional, dengan jumlah sampel sebanyak 28 responden wanita usia subur (WUS) yang dipilih menggunakan tekhnik simple random sampling. Hasil uji statistik dengan menggunakan uji Chi Square, didapatkan $p$ value sebesar $0.008, p$ value $<0.05$ yang berarti bahwa terdapat hubungan antara Tingkat Pengetahuan Dengan Kemampuan Pemeriksaan Dada Sendiri (SADARI) Pada Wanita Usia Subur. Peneliti selanjutnya dapat meneliti tentang analisis faktor yang dapat mempengaruhi kesadaran dan kemauan wanita dalam melakukan SADARI.
\end{abstract}

Kata Kunci : Pengetahuan, Kemampuan, Pemeriksaan Dada Sendiri

\section{PENDAHULUAN}

Kanker merupakan penyakit tidak menular yang diakibatkan oleh sel maupun jaringan tidak normal, pertumbuhan dan perkembangannya sangat cepat sehingga dapat menggangu proses metabolisme tubuh (Kemenkes RI, 2018). Terdapat beberapa tanda dan gejala kanker payudara diantaranya; ketika diraba terdapat benjolan dan tidak terasa nyeri, perubahan kulit payudara, pengerasan kulit dan seperti kulit jeruk permukaannya, terdapat luka yang sembuhnya lama pada payudara, serta putting susu mengeluarkan cairan (P2PTM Kemenkes RI, 2019).

Kanker merupakan penyebab kematian ketiga terbanyak di Indonesia dengan jumlah kematian sebanyak 207.210 jiwa pada tahun 2018 (Kemenkes RI, 2020). Berdasarkan data yang ditulis oleh P2PTM Kemenkes RI (2018) menyebutkan bahwa penderita kanker payudara dan kanker leher Rahim tahun 2018 meningkat dibandingkan tahun 2017 yang lalu. Peningkatan sekitar $0,4 \%$ dari tahun 2013 sebesar 1,4\% kemudian menjadi $1,8 \%$ di tahun 2018 (Riskesdas, 2018). Di Asia Tenggara Indonesia menempati rangking kedelapan dengan jumlah penderita kanker sebanyak 136,2 per 100.000 jiwa, sedangkan penderita kanker payudara sebesar 42,1 per 100.000 jiwa (Kemenkes, 2019).

Kanker payudara merupakan salah satu kanker yang paling sering diderita oleh perempuan di seluruh dunia. Meskipun ilmu kesehatan, diagnosis dini dan peningkatan kesadaran masyarakat sudah mengalami 
kemajuan namun kanker payudara masih tetap menjadi penyakit yang mengancam jiwa. Perlu adanya deteksi dini untuk mengurangi ancaman tersebut (Erbil \& Bolukbas, 2012), salah satu skrining yang bisa dilakukan untuk mendeteksi kanker payudara yaitu melakukan pemeriksaan dada sendiri (SADARI). SADARI sangat penting dilakukan untuk mengetahui adanya kelainan pada payudara wanita, apabila terdapat benjolan atau gejala kanker segera terdeteksi dan terdiagnosis lebih awal sehingga risiko kematian akibat kanker payudara dapat ditekan (Babu, et al., 2011; Montocciolo, et al., 2018). Studi penelitian menyebutkan bahwa morbiditas dan mortalitas telah terbukti berkurang secara efektif dengan melakukan deteksi dini kanker payudara melalui kegiatan skrining (BaronEpel, Friedman, Lernau, 2009; Bener, et al., 2009; Cohen \& Azaiza, 2010). Pemeriksaani dada sendiri merupakan bagian penting dalam meningkatkan kesehatan setiap perempuan, dimana pemeriksaan tersebut dapat membantu mendeteksi masalah sebelum perempuan merasakan gejala dan memberi kesempatan untuk mendapatkan pengobatan dan pencegahan sejak dini (Depkes RI, 2009).

Uraian diatas menunjukkan masih terjadi peningkatan angka kejadian kanker payudara, sehingga diperlukan optimalisasi untuk pencegahan dan pengendalian kejadian kanker payudara maka melakukan skrining awal dengan pemeriksaan dada sendiri (SADARI) sangat penting dan perlu dilakukan oleh setiap wanita. Berdasarkan uraian tersebut peneliti tertarik melakukan penelitian yang bertujuan untuk mengetahui hubungan Tingkat Pengetahuan Dengan Kemampuan Pemeriksaan Dada Sendiri (SADARI) Pada Wanita Usia Subur Di Desa Sukodadi Kecamatan Wagir Kabupaten Malang.

\section{METODE PENELITIAN}

Penelitian ini dilakukan di Desa Sukodadi Kecamatan Wagir Kabupaten Malang pada tanggal 25 April 2020. Metode penelitian yang digunakan dalam penelitian ini yaitu Cross Sectional. Populasi dalam penelitian adalah seluruh wanita usia subur di Desa Sukodadi dengan jumlah sampel sebanyak 28 responden wanita usia subur (WUS), yang telah memenuhi kriteria inklusi dan diambil secara simple random sampling. Peneliti memberikan penjelasan sebelum penelitian berlangsung dan responden diminta untuk mengisi lembar persetujuan penelitian. Instrumen penelitian menggunakan lembar kuesioner pengetahuan SADARI diisi oleh resonden dan lembar observasi kemampuan SADARI diisi oleh peneliti dengan cara mengamatan secara visual. Selanjutnya data dianalisa dengan menggunakan uji statistik yang yaitu uji Chi Square pada SPSS 16.

\section{HASIL PENELITIAN}

Berdasarkan hasil penelitian didapatkan data umum dan data khusus responden sebagai berikut :

Tabel 1. Karakteristik Responden Berdasarkan Tingkat Pendidikan Pada Wanita Usia Subur Di Desa Sukodadi Kecamatan Wagir Kabupaten Malang

\begin{tabular}{ccc}
\hline Pendidikan & Frekuensi (n) & Persentase (\%) \\
\hline SD & 7 & 25 \\
SMP & 11 & 39.4 \\
SMA & 8 & 28.6 \\
Perguruan Tinggi & 2 & 7 \\
\hline Total & $\mathbf{2 8}$ & $\mathbf{1 0 0}$ \\
\hline
\end{tabular}

Berdasarkan Tabel 1 dapat diketahui bahwa hampir setengah dari responden berpendidikan SMP yaitu sebanyak 11 responden $(39,4 \%)$.

Tabel 2. Hubungan Tingkat Pengetahuan Dengan Kemampuan Pemeriksaan Dada Sendiri (Sadari) Pada Wanita Usia Subur Di Desa Sukodadi Kecamatan Wagir Kabupaten Malang 


\begin{tabular}{ccccc}
\hline & \multicolumn{2}{c}{ Kemampuan SADARI WUS } & Total & $\begin{array}{c}\boldsymbol{p} \text { palue } \\
\text { (Chi Square) }\end{array}$ \\
\cline { 2 - 4 } Pengetahuan SADARI WUS & $\begin{array}{c}\text { Tidak } \\
\text { Mampu }\end{array}$ & Mampu & & \\
\cline { 2 - 5 } & $\mathbf{f}$ & $\mathbf{f}$ & $\mathbf{n}$ & \\
\hline Rendah & 8 & 0 & 8 & 0.008 \\
Tinggi & 8 & 12 & 20 & \\
\hline Total & 16 & 12 & $\mathbf{2 8}$ & \\
\hline
\end{tabular}

Berdasarkan Tabel 2. Didapatkan hasil bahwa $p$ value sebesar 0.008 dari hasil uji statistik dengan menggunakan uji Chi Square.

\section{PEMBAHASAN}

Berdasarkan Tabel 1. Didapatkan hasil bahwai hampir setengah dari responden berpendidikan SMP. Hasil penelitian lain menunjukan bahwa hampir sebagian responden mempunyai pendidikan dasar sebanyak $46.67 \%$ dan sebagian mempunyai tingkat pengetahuan SADARI yang kurang (Musyahida; Masse, 2017) Menurut penelitian yang dilakukan oleh Mariana, Syarniah, Norhemalisa (2017) didapatkan hasil bahwa respondeni yang mempunyaii tingkatan pendidikan rendah cenderung imemiliki pengetahuani yang kurangi tentangl SADARI. Hal ini sejalan dengan hasill penelitiani yang dilakukan oleh Arafah dan Notobroto (2017) yang menunjukkani bahwa iibu rumah itangga yang mempunyai pengetahuan kurang baiki tentangi SADARI cenderungi tidak imelakukan SADARI. Sebuah hasil penelitian menunjukkan bahwa perempuan yang tinggal dimasyarakat di Nigeria memiliki pengetahuan yang rendah tentang kanker payudara dan perilaku periksa payudara sendiri, dimana pendidikan menjadi salah satu penentu utama tingkat pengetahuan dan perilaku kesehatan diantara responden penelitian (Okobia et al, 2006). Notoatmodjo (2008) mengungkapkan bahwa tingkat pengetahuan seseorang pada umumnya dipengaruhii oleh faktor ipendidikan, dimana isemakin tinggi tingkat pendidikan seseorang maka akan semakin imudah menerimai informasi seiring dengan hal tersebut pengetahuannya juga akan semakin meningkat.

Berdasarkan Tabel 2. Dapat disimpulkan bahwai terdapat hubungan antara Tingkat Pengetahuan Dengan Kemampuan Pemeriksaan Dada Sendiri (SADARI) Pada Wanita Usia Subur Di Desa
Sukodadi Kecamatan Wagir Kabupaten Malang. Menurut Notoatmodjo (2010) menjelaskan bahwa pengetahuan ialah salah satu faktor yang cenderung mempengaruhi perilaku seseorang. Seseorang yang didasari oleh pengetahuan yang baik maka akan menunjukkan perilaku yang baik pula. Hasil penelitian yang dilakukan oleh Wulandari dan Ayu (2017) menunjukkan bahwa terdapat hubungan yang kuat antara pengetahuan dan sikap dengan perilaku SADARI pada mahasiswi PGSD STKIP Muhammadiyah Kuningan. Maesaroh (2016) menyimpulkan dalam penelitiannya bahwa terdapat hubungan antara pengetahuani wanitai usia isubur dengan sikapi terhadap SADARI di Karang Malang RW 004 Jetis Juwiring Klaten. Hal ini sebanding dengan penelitian yang dilakukan oleh Amier dan Djawarut (2014) hasil penelitiannya menunjukan bahwa terdapat hubungan yang kuat antara pengetahuan, kecemasan, ketakutan dengan SADARI pada siswi SMK PGRI Minasatene. Hasil penelitian lain juga menyebutkan bahwa terdapat hubungan pengetahuan dan isikap WUS terhadap iperilaku pemeriksaan payudara sendiri (SADARI) (Ekanita; Khosidah, (2013). Sesuai dengan penelitian yang dilakukan oleh Erbil \& Bolukbas (2012) yang menyimpulkan dalam penelitiannya bahwa keyakinan, sikap dan perilaku kesehatan seorang perempuan itu dipengaruhi secara positif oleh pengetahuan seorang perempuan tersebut tentang risiko dan manfaat deteksi dini kanker payudara.

Hasil penelitian yang dilakukan oleh Hajian-Tilaki dan Auladi (2014) menunjukkan bahwa terdapat hubungan yang erat antara sikap positif terhadap manfaat yang dirasakan, keyakinan yang dirasakan/self efficacy dan motivasi kesehatan dengan melakukan pemeriksaan payudara sendiri. 
Sebuah penelitian juga menyimpulkan bahwa program promosi kesehatan payudara efektif dalam meningkatkan frekuensi pemeriksaan payudara sendiri terhadap wanita Turki, selain itu bermanfaat dalam meningkatkan pengetahuan tentang kesehatan payudara, meningkatkan kepercayaan diri dalam melakukan pemeriksaan payudara sendiri dan kepercayaan kesehatan juga mengalami peningkatan terhadap sebagian wanita (Secginli \& Nahcivan, 2011). Perlunya mendidik masyarakat tentang deteksi dini kanker payudara melalui skrining menjadi sangat penting, selain itu pemeriksaan payudara sendiri merupakan metode yang efektif untuk menentukan diagnosisis secara dini (Rutledge et al, 2001; Chong et al, 2002).

Sebuah study menyimpulkan bahwa program pendidikan kesehatan sangatlah penting untuk meningkatkan kesadaran dan meningkatkan sikap terhadap metode skrining kanker payudara diantaranya adalah pemeriksaan payudara sendiri (Aljohani, et al 2016). Kesimpulan dalam sebuah penelitian menyebutkan bahwa terdapat persentase yang cukup tinggi pada responden yang memiliki pengetahuan kurang dan sikap negatif cenderung kurang mampu melakukan pemeriksaan payudara sendiri pada saat pre-test. Penelitian ini juga menyimpulkan bahwa dampak yang ditimbulkan dari program pendidikan Health Belief Model terhadap pengetahuan, kepercayaan dan pemeriksaan payudara

\section{DAFTAR PUSTAKA}

Aljohani S., Saib I., Noorelahi M. (2016). Women's Performance of Breast Cancer Screening (Breast SelfExamination, Clinical Breast Exam and Mammography). Journal of Health Education Research \& Development. Vo. 4. No. 4. P: 1-5.

Amier, H. dan Djawarut, H. 2014. FaktorFaktor Yang Berhubungan Dengan Pemeriksaan Payudara Sendiri (SADARI) Pada Siswi SMK PGRI Kab. Pangkep. Jurnal IImiah Kesehatan Diagnosis. Vol. 5. No. 2. Hal: 157-164.

Babu, G. R., Samari, G., Cohen, S. P., Mahapatra, T., Wahbe, R. M., Mermash, S., Galal, O. M. (2011). Breast Cancer Screening Among sendiri cukup positif (Mohamed et al, 2016). Kesimpulan dalam sebuah penelitian menyebutkan bahwa pendidikan kesehatan tentang pemeriksan payudara sendiri menjadi sangat penting bagi perempuan, karena pemeriksaan payudara sendiri (SADARI) merupakan salah satu langkah sederhana untuk mendeteksi kanker payudara. Selain itu seorang perempuan akan lebih termotivasi dan lebih percaya diri dalam melakukan pemeriksaan payudara sendiri (Gonzales et al, 2018). Hasil penelitian lain juga menyebutkan bahwa terdapat hubungan yang signifikan antara usia, tingkat pendidikan dan pengetahuan tentang metode skrining kanker payudara dengan melakukan pemeriksaan payudara sendiri (Ighodaro \& Akhigbe, 2016).

\section{KESIMPULAN DAN SARAN}

Hasil penelitian ini menunjukkan bahwa semakin tinggi tingkat pengetahuan SADARI maka wanita usia subur mampu melakukan SADARI. Terdapat hubungan yang signifikan antara Tingkat Pengetahuan Dengan Kemampuan Pemeriksaan Dada Sendiri (SADARI) Pada Wanita Usia Subur Di Desa Sukodadi Kecamatan Wagir Kabupaten Malang.

Bagi peneliti selanjutnya diharapkan dapat meneliti tentang analisis faktor yang dapat mempengaruhi kesadaran dan kemauan wanita dalam melakukan SADARI.

Females in Iran and Recommendations for Improved Practice: A ReviewJournal: Asian Pacific of Cancer Prevention. Vol. 12. PP. 1519-1527.

Baron-Epel O, Friedman N, Lernau O. (2009). Reducing disparities in mammography-use in a multicultural population in Israel. Journal: International Journal Equity Health. Vol. 8. PP. 19-30.

Bener A, El Ayoubi H, Moore M, Basha B, Joseph S, Chouchane L. (2009). Do we need to maximize the breast cancer screening awareness? Experience with an endogamous society with high 
fertility. Journal: Asian Pacific of Cancer Prevention. Vol. 10. PP. 1-6.

Cohen M, \& Azaiza F (2010). Increasing breast examinations among Arab women using a tailored culture based intervention. Journal: Behavioral Medicine. Vol. 36. PP. 92-9.Ekanita, P. dan Khosidah, A. 2013. Hubungan Antara Pengetahuan Dan Sikap Wus Terhadap Perilaku Pemeriksaan Payudara Sendiri (Sadari). Jurnal Ilmiah Kebidanan. Vol. 4. No. 1. Hal: 167-177.

Chong PN, Krishnan M, Hong CY, Swah TS. (2002). Knowledge and practice of breast cancer screening amongst public health nurses in Singapore. Singapore Medical Journal. Vol. 43. No. 10. PP: 509-516.

Depkes RI. (2009). Dirjen Pemberantasan Penyakit dan Penyehatan Lingkungan "Pencegahan Kanker Rahim dan Kanker Payudara". Jakarta: Depkes RI.

Erbil, N \& Bolukbas, N. (2012). Beliefs, Attitudes, and Behavior of Turkish Women about Breast Cancer and Breast Self-Examination According to a Turkish Version of the Champion Health Belief Model Scale. Journal: Asian Pacific of Cancer Prevention. Vol. 13. PP. 5823-5828.

Gonzales A., Alzaatreh M., Mari M., Saleh A. A., Alloubani A. (2018). Beliefs and Behavior of Saudi Women in the University of Tabuk Toward Breast Self Examination Practice. Asian Pacific Journal of Cancer Prevention. Vol. 19. No. 1. PP: 121-126.

Hajian-Tilaki, K., Auladi, S. (2014). Health Belief Model And Practice Of Breast Self-Examination And Breast Cancer Screening In Iranian Women. Journal: Breast Cancer. Vol. 21. PP: 429-434.

Ighodaro E. O., Akhigbe A. O. (2016). Knowledge Of Breast Cancer Screening Methods And The Practice Of Breast Self-Examination Among Female Nursing Students In A Nigerian Teaching Hospital. East African Medical Journal. Vol. 33. No. 11. PP: 599-605.

Kemenkes RI. (2020). Jenis Kanker ini Rentan Menyerang Manusia. (Online). Diakses dari https://www.kemkes.go.id/article/view/2 0011400002/jenis-kanker-ini-rentanmenyerang-manusia.html

Kemenkes RI. (2019). Hari Kanker Sedunia 2019. (Online). Diakses dari

https://www.kemkes.go.id/article/view/1 9020100003/hari-kanker-sedunia2019.html

Maesaroh, S. 2016. Hubungan Pengetahuan Dan Sikap Wanita Usia Subur Terhadap Sadari Di Karang Malang Rw 004 Jetis Juwiring Klaten. Jurnal Kebidanan Indonesia. Vol. 7. No. 2

Mariana, E. R., Syarniah, Norhemalisa, S. 2018. Pengetahuan Wanita Usia Subur (Wus) Tentang Pemeriksaan Payudara Sendiri (Sadari) Di Desa Maniapun. Jurnal Pendidikan Kesehatan. Vo. 7. No. 1. Hal: 1-9

Musyahida dan Masse, N. A. 2017. Pengetahuan Wanita Usia Subur Tentang Pemeriksaan Payudara Sendiri (Sadari). Jurnal Kesehatan Lentera Acitya. Vol 4. No. 4. Hal: 4955.

Mohamed H. A., Ibrahim Y. M., Lamadah S. M., El-Magd M. H. A. (2016). Application of the Health Belief Model for Breast Cancer Screening and Implementation of Breast SelfExamination Educational Program for Female Students of Selected Medical and Non-Medical Faculties at Umm al Qura University. Life Science Journal. Vol. 13. No. 5. PP: 21-33.

Monticciolo, D. L., Newell, M. S., Moy, L., Niell, B., Monsees, B., Sikles, E. A. (2018). Breast Cancer Screening in Women at Higher-Than-Average Risk: Recommendations From the ACR. Journal: American College of Radiology. Vol. 15. PP. 408-414.

Notoatmodjo, S. 2008. Metodelogi PenelitianKesehatan. Jakarta: Rineka Cipta.

Notoatmodjo, S. 2010. Pendidikan dan Perilaku Kesehatan. Jakarta: Rineka Cipta.

Okobia MN, Bunker $\mathrm{CH}$, Okonofua FE, Osime U. (2006). Knowledge, attitude and practice of Nigerian women towards breast cancer: A crosssectional study. World Journal of Surgical Oncology. Vol. 4. No. 11. PP: 1-9. 
P2PTM Kemenkes RI. (2019). Waspada Gejala Kanker Payudara. (Online). Diakses dari http://p2ptm.kemkes.go.id/infographicp2ptm/penyakit-kanker-dan-kelainandarah/waspada-gejala-kankerpayudara

P2PTM Kemenkes RI. (2018). Peringatan Hari Kanker Sedunia 2018. (Online). Diakses dari http://p2ptm.kemkes.go.id/peringatanhari-kanker-sedunia-2018

Riskesdas. (2018). Hasil Utama Riskesdas. (Online). Diunduh dari https://www.kemkes.go.id/resources/do wnload/info-terkini/hasil-riskesdas2018.pdf

Rutledge DN, Barsevick A, Knobf MT, Bookbinder M. (2001). Breast Cancer Detection: Knowledge, Attitudes, and
Behaviors of Women From Pennsylvania. Journal: Oncology Nursing Forum. Vo. 28. No. 6. PP:1032-1040.

Secginli S., Nahcivan N. O. (2011). The Effectiveness Of A Nurse-Delivered Breast Health Promotion Program On Breast Cancer Screening Behaviours In Non-Adherent Turkish Women: A Randomized Controlled Trial. International Journal of Nursing Studies. Vo. 48. No. 1. PP: 24-36.

Wulandari, F. dan Ayu, S. M. 2017. Hubungan Tingkat Pengetahuan dan Sikap Dengan Perilaku Pemeriksaan Payudara Sendiri (SADARI) Mahasiswi. Prosiding Seminar Nasional IKAKESMADA. "Peran Tenaga Kesehatan dalam Pelaksanaan SDGs". Hal: 137-144. 